\title{
NAOMOBBY, development of a computer vision and robotics-based software tool to support rehabilitation in upper limb physical therapies
}

\author{
NAOMOBBY, desarrollo de una herramienta software basada en visión por \\ computador y robótica para apoyar la rehabilitación en terapias físicas de \\ miembros superiores
}

\author{
C. E Fernández-Álvarez (iD , B. Bacca-Cortes ; J. A. Buitrago ; ; E. F. Caicedo-Bravo
}

\begin{abstract}
Nowadays, $21 \%$ of Colombian population, and the $35 \%$ of the population in Cauca Valley have limited movement of body, arms, hands or legs. Then, the quality of life of these people is highly affected, since they have limitations in daily living activities. Physical rehabilitation therapies allow the restoration of movement and maximum functional capacity in people. Successful physical therapies depend on empathy and motivation with the rehabilitation process (RP), then the more empathy of patients with the RP, the more patient willingness regarding the rehabilitation therapy. Motivation is crucial in rehabilitation, and it is used as a fundamental rehabilitation out-come. This work has the aim to present the software tool called NAOMOBBY to support physical rehabilitation therapies of shoulder, elbow and wrist joints. NAOMOBBY includes a GUI for therapist, a Kinect sensor and an interactive humanoid robot NAO to increase the patient willingness regarding the RP. NAOMOBBY includes the following modules: configuration/management, movement reproduction, and results report using GAS methodology. NAOMOBBY was tested using quantitative and field tests. Quantitative tests measure the error in the Kinect sensor of the NAO robot joint motions to bring users a suitable feedback. Quantitative results were obtained using three basic functional motions. The mean square error for these three motions were $0,373 \%, 0,096 \%$, and $1,129 \%$ respectively. Field tests were conducted at the SURGIR neuro-rehabilitation center using 3 physiotherapists who considered the NAOMOBBY software tool as a novel, easy to use, and that encourage patients to perform the physical therapy.
\end{abstract}

Index Terms - Kinect sensor; NAO robot; natural user interface; physical therapies.

This manuscript was sent on January 20, 2020 and accepted on June 10, 2020. This work was partially funded by the research project "Methodological proposal to use robotics in therapies to develop physical and cognitive skills in children with motor disability" contract CI2851 of the Universidad del Valle

C. Fernández, is with the School of Electrical and Electronics Engineering, University of Valle, Ciudad Universitaria Meléndez, Calle 13 \# 100-00, Cali, Colombia (e-mail: cristhian.fernandez@ correounivalle.edu.co)

B. Bacca-Cortes, is with the School of Electrical and Electronics Engineering, University of Valle, Ciudad Universitaria Meléndez, Calle 13 \# 100-00, Cali, Colombia (e-mail: bladimir.bacca@ correounivalle.edu.co)
Resumen-Actualmente, el $21 \%$ de la población en Colombia y el $35 \%$ de la población del Valle del Cauca tiene limitaciones en el movimiento del cuerpo, brazos, manos o piernas. Entonces, la calidad de vida de estas personas está altamente afectado, ya que ellas tienen limitaciones al desarrollar actividades del diario vivir. La rehabilitación a través de la terapia física, permite la restauración del movimiento y la máxima capacidad funcional en las personas. Terapias físicas exitosas dependen de la empatía y motivación con el proceso de rehabilitación (PR), entonces entre más alta la empatía de los pacientes con el PR, más alta la disposición será de los pacientes en relación con la terapia de rehabilitación. Motivación es crucial en rehabilitación, y es usado como un resultado determinante de la rehabilitación. Este trabajo tiene el objetivo de presentar la herramienta software llamada NAOMOBBY para soportar las terapias de rehabilitación física de las articulaciones de hombro, codo y muñeca. NAOMOBBY incluye una GUI para terapeutas, un sensor Kinect $y$ un robot interactivo humanoide NAO con el fin de incrementar la disposición del paciente hacia el PR. NAOMOBBY incluye los siguientes módulos: configuración y gestión, reproducción de movimiento y reporte de resultados usando la metodología GAS. NAOMOBBY fue probada usando pruebas cuantitativas y de campo. Las pruebas cuantitativas miden el error en el sensor Kinect de los movimientos de las articulaciones del robot NAO, con el fin de brindar a los usuarios una adecuada realimentación. Los resultados cuantitativos fueron obtenidos usando tres movimientos funcionales básicos. Los errores cuadráticos medios de estos tres movimientos fueron $0,373 \%, 0,096 \%$, y $1,129 \%$ respectivamente. Las pruebas de campo fueron realizadas en el centro de neuro-rehabilitación SURGIR usando 3 fisioterapeutas quienes consideraron a la herramienta software NAOMOBBY como novedosos, fáciles de usar y que motiva a los pacientes a realizar la terapia física.

J. Buitrago is with the Electronics Engineering Program, University of Quindío, Cra. 15 Street 12 North, Armenia, Colombia (e-mail: jalbertob@uniquindio.edu.co).

E. Caicedo, is with the School of Electrical and Electronics Engineering, University of Valle, Ciudad Universitaria Meléndez, Calle 13 \# 100-00, Cali, Colombia (e-mail: eduardo.caicedo@correounivalle.edu.co) 
Palabras claves - Interfaz natural de usuario; sensor Kinect; robot NAO; terapias físicas.

\section{INTRODUCTION}

$\mathrm{A}$ $\mathrm{S}$ reported in [1], $21 \%$ of Colombian population, and the $35 \%$ of the population in Cauca Valley have limited movement of body, arms, hands or legs. In addition, it is worth noting that the $3.7 \%$ (4.1\% in Cauca Valley) of this population says "They do not like" the rehabilitation method provided. Although, the 2010 census conducted by DANE does not details other reasons why people do not like the rehabilitation method. Then, current technologies such as the Natural User Interfaces (NUI) [2] can be used to improve the rehabilitation experience.

Physical rehabilitation therapy is a reinforcement for patients with musculoskeletal and postural difficulties. These difficulties can be treated with different methods, actions and techniques, through the application of physical means such as movement, therapeutic exercises, massages and others. Physical therapy aims to facilitate the development, maintenance and recovery of the maximum functionality and mobility of the individual or group of people [3].

To do so, classical physical rehabilitation therapy methods involve repetitive movements, exercises and massages. However, merging the current NUI technologies, mobile robotics and classical physical rehabilitation therapies, new strategies can be developed to support the rehabilitation process.

The development of humanoid robots with high movement capabilities have favored their use in therapies. These robots are used interactively in physical exercises with patients, to encourage them to continue with their therapy exercises [4]. Patients interaction is an effective way to capture their attention, creating a pleasant rehabilitation process.

Introducing robots and increasing patient interaction encourage patients' empathy with respect to the rehabilitation process. Then, long and monotonous physical rehabilitation therapies can achieve their therapeutic objectives. In this context, this work presents the development of NAOMOBBY software tool to support physical rehabilitation therapies of shoulder, elbow and wrist. Fig. 1 shows the system setup for NAOMOBBY, here the therapist interacts directly with NAOMOBBY GUI to manage the therapeutic goals, and patient's data; once the physical therapy is defined, the NAO robot shows to patients the motions to perform, then patients motions are captured using the Kinect sensor for validation; also, NAOMOBBY reports the physical therapy results using the GAS methodology [5]. This is done in order to quantify the patient's progress quantitatively.

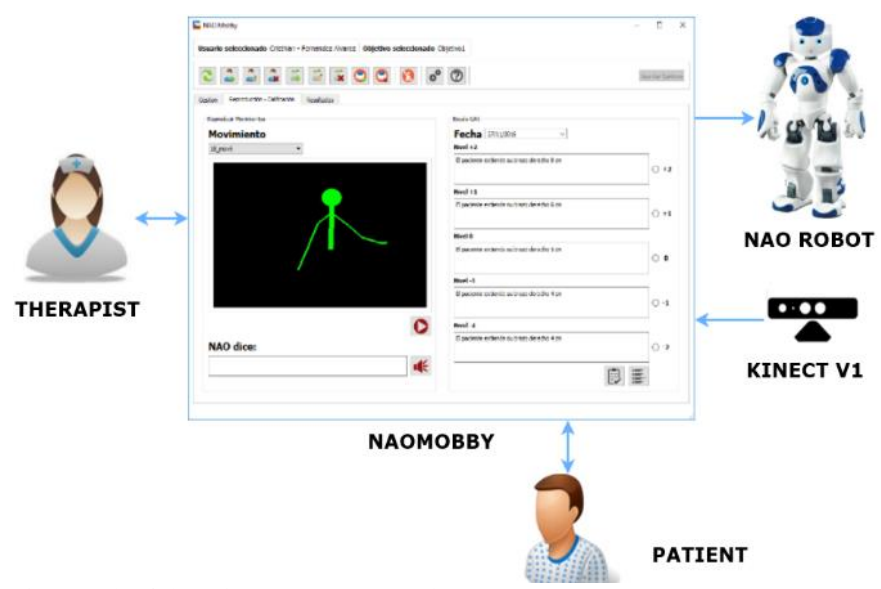

Fig. 1. Playful environment setup and NAOMOBBY.

This work has two main contributions: first, NAOMOBBY automates the measurement of the rehabilitation process based on the GAS methodology; and second, NAOMOBBY consolidates in a graphical way the rehabilitation process for upper limbs, starting at patient's data registration, and ending at the therapy report considering the Colombian rehabilitation processes.

This paper is organized as follows: Section II presents the related works. Section III shows the development details of NAOMOBBY. Section IV describes the results obtained. And, Section $\mathrm{V}$ presents our conclusions.

TABLE I

RELATED WORKS

\begin{tabular}{|c|c|c|c|c|c|c|c|c|c|}
\hline Ref. & Plat. & Sens. & Int. & Input & Pers. & Move & Fbk. & Limbs & Report \\
\hline$[6]$ & PLEO & $\begin{array}{l}\text { Touch, } \\
\text { Voice }\end{array}$ & $\begin{array}{l}\text { Sound, } \\
\text { body } \\
\text { gestures }\end{array}$ & Buttons & No & No & $\begin{array}{l}\text { Visual, } \\
\text { sound }\end{array}$ & No & Therapist \\
\hline [7] & $\begin{array}{l}\text { Armeo- } \\
\text { Spring }\end{array}$ & Motion & $\begin{array}{l}\text { Sound, } \\
\text { Video }\end{array}$ & $\begin{array}{c}\text { GUI, } \\
\text { switches }\end{array}$ & Yes & Yes & $\begin{array}{l}\text { Visual, } \\
\text { sound }\end{array}$ & Full arm & Therapist \\
\hline$[8]$ & NAO & $\begin{array}{l}\text { Touch, } \\
\text { voice, } \\
\text { camera }\end{array}$ & $\begin{array}{c}\text { Sound, } \\
\text { body } \\
\text { gestures }\end{array}$ & Camera NAO & No & No & $\begin{array}{l}\text { Visual, } \\
\text { sound }\end{array}$ & Arms & No \\
\hline [10] & NAO & $\begin{array}{l}\text { Touch, } \\
\text { voice, } \\
\text { camera }\end{array}$ & $\begin{array}{l}\text { Sound, } \\
\text { body } \\
\text { gestures }\end{array}$ & $\begin{array}{c}\text { Cameras, } \\
\text { GUI }\end{array}$ & Yes & No & $\begin{array}{l}\text { Visual, } \\
\text { gestures }\end{array}$ & Arms, legs & No \\
\hline [11] & NAO & $\begin{array}{l}\text { Touch, } \\
\text { voice, } \\
\text { Kinect }\end{array}$ & $\begin{array}{l}\text { Sound, } \\
\text { body } \\
\text { gestures }\end{array}$ & Kinect, GUI & Yes & Yes & $\begin{array}{l}\text { Visual, } \\
\text { gestures }\end{array}$ & Arms, legs & Therapist \\
\hline
\end{tabular}




\begin{tabular}{|c|c|c|c|c|c|c|c|c|c|}
\hline [13] & Kinect & $\begin{array}{l}\text { RGBD } \\
\text { camera }\end{array}$ & $\begin{array}{l}\text { Sound, } \\
\text { videoss }\end{array}$ & GUI, Kinect & Yes & Yes & $\begin{array}{l}\text { Visual, } \\
\text { sound }\end{array}$ & Arms & Therapist \\
\hline [14] & VR & - & $\begin{array}{l}\text { Sound, } \\
\text { gestures }\end{array}$ & VR, switches & Yes & No & $\begin{array}{l}\text { Visual, } \\
\text { sound }\end{array}$ & Legs & Therapist \\
\hline [15] & NAO & $\begin{array}{l}\text { Touch, } \\
\text { camera }\end{array}$ & $\begin{array}{l}\text { Sound, } \\
\text { gestures }\end{array}$ & GUI & Yes & No & $\begin{array}{l}\text { Visual, } \\
\text { sound }\end{array}$ & Arms, legs & Therapist \\
\hline [16] & Robot Arm & $\begin{array}{l}\text { Touch, } \\
\text { pressure }\end{array}$ & $\begin{array}{l}\text { Sound, } \\
\text { video }\end{array}$ & $\begin{array}{l}\text { Joystick, } \\
\text { touch-screen }\end{array}$ & Yes & No & $\begin{array}{l}\text { Visual, } \\
\text { sound }\end{array}$ & Arms & Therapist \\
\hline [17] & NAO & Kinect & $\begin{array}{l}\text { Sound, } \\
\text { body } \\
\text { gestures }\end{array}$ & Kinect, GUI & Yes & Yes & $\begin{array}{l}\text { Visual, } \\
\text { sound }\end{array}$ & Arms & Therapist \\
\hline [18] & NAO & $\begin{array}{l}\text { Touch, } \\
\text { camera }\end{array}$ & $\begin{array}{l}\text { Sound, } \\
\text { body } \\
\text { gestures }\end{array}$ & GUI & No & No & $\begin{array}{l}\text { Visual, } \\
\text { sound }\end{array}$ & No & Therapist \\
\hline [19] & NAO & Touch & $\begin{array}{l}\text { Sound, } \\
\text { body } \\
\text { gestures }\end{array}$ & GUI, buttons & No & No & $\begin{array}{l}\text { Visual, } \\
\text { sound }\end{array}$ & No & Therapist \\
\hline [20] & NAO & $\begin{array}{l}\text { IMU, } \\
\text { Kinect, } \\
\text { cameras }\end{array}$ & $\begin{array}{l}\text { Sound, } \\
\text { body } \\
\text { gestures }\end{array}$ & GUI & No & Yes & $\begin{array}{l}\text { Visual, } \\
\text { sound }\end{array}$ & No & Therapist \\
\hline
\end{tabular}

\section{RELATED WORKS}

Table 1 shows the state of the art of the most relevant works related with this paper. Each related work was compared considering the following properties: the robot platform (Plat.), sensors used (Sens.), type of interaction with users (Int.), input interfaces (Input), data persistence (Pers.), user motion validation (Move), users' feedback (Fbk.), limbs used in the physical therapy, and type of report used.

In [6] at Sant Joan de Déu Hospital, the PLEO DinoRobot was used in order to do cognitive and physical rehabilitation of patients with head brain trauma. This robot acts like a pet, it responses to the children contact and voice. Then, it achieves good empathy with patients. But, neither the motion validation is performed nor a therapy report is made.

A different approach is presented in [7] with the ArmeoSpring platform. Where, the robot has a physical interaction with patients in order to perform physical rehabilitation to people with movement alterations in arms and hands. Again, gamming is used over many physical functional exercises to achieve full focus of patients in the rehabilitation therapy.

Lack of concentration is a persistent problem in physical rehabilitation therapies. In [8] authors used a NAO robot in order to gain attention of autistic children in two interesting ways: face gesture recognition using vision, and musical interaction through a percussion instrument. Both cases, encourage social skills of children, and increase the empathy for the therapy process. However, all data concerning to the rehabilitation process is held manually, as well as, authors do not mention how to measure the progress of the rehabilitation therapy.

The human body is used to perform primary motor movements, or express emotions. [9] and [10] are works focused in these two aspects. In [9], authors used the NAO robot to help children to identify and express 9 different body gestures. And, in [10], authors used the NAO robot to teach children primary motor movements. In both cases, the user movement is not validated, nor the therapy progress is measured.

Validating the user motion has the advantage of performing a quantitative evaluation of user motions. In [11], authors used the Kinect sensor to command the NAO robot, in this case, the
NAO robot imitates the user motion. In addition, the NAO robot interacts with children using speech and eyes expressions. In this context, in [13] the Kinect sensor is also used to validate the user motions in order to test primary motors skills in legs and arms. This work proposes a low cost platform to perform physical therapies in presence of a therapist, or at home. In this way, it increases the amount of time dedicated to physical rehabilitation. In [16], authors proposes another portable low cost platform to facilitate isolated movements for hemiplegia patients. In this case, a mobile device and an electronic lever interacts with users in physical therapies. These works are focused on gaming and physical interaction, where therapists are in charge of assess the therapy progress. The latter may issue subjective opinions, which are difficult to quantify.

The NAO robot has also been used for rehabilitation exercises in upper limbs. In [17] a software architecture was presented that allows the NAO robot to carry out rehabilitation therapies of upper limbs, in patients with physical disabilities. In [17] , authors use the Kinect sensor to monitor the patient's movement, and the NAO robot as a social assistive robot in order to increase their commitment to therapy.

Physical rehabilitation therapies of legs include exercises over long periods of time. Then, motivation and concentration are very difficult to achieve when therapists work with children. In [12], the NAO robot was used to support these therapies at the Royal Children Hospital at Melbourne. As a result, children performance and motivation were better when the NAO robot was present. In [12], the therapist has no direct interaction with patients, but he/she is present in the therapy; also, therapists are in charge of tracking the rehabilitation process. However, in [15] the NAO robot is the only one agent who interacts with autistic children. The therapist is behind the scenes using a camera as video-feedback in order to track the rehabilitation process. This proposal tries to not overwhelm autistic children with people gestures.

Virtual reality is a popular bio-feedback method introduced in physical rehabilitation therapies. In [14], authors propose a rehabilitation tool including virtual reality and an electric treadmill to perform physical rehabilitation of neurologically caused gait impairments. As a result, patients achieved the therapeutic objectives faster in comparison with conventional gait therapies. 
Increasing social and motor skills in autism patients is another active field of research where a motion-based rehabilitation therapy can be applied. In [18], [19] and [20] authors propose different approaches to increase children's attention, and social interaction using the NAO robot, and different experimental setups. However, these works do not mention how the therapy process is assessed, nor what kind of tools can be used for therapists to manage the rehabilitation therapy.

Considering the works reviewed, it is worth highlighting that it is important to provide to patients a feedback of their actions; the motion validation is crucial to have evidence about the patient movements quality; also, different sensors and interaction devices can be used to enrich the experience into the rehabilitation therapy; and, all these factors contribute to increase the patients' motivation and empathy with the rehabilitation process. However, the works reviewed in Table 1 do not have a methodology to measure objectively the rehabilitation process progress, basically the therapist is in charge of doing this task, which may be subject to subjective opinions.

\section{DEVELOPMENT OF NAOMOBBY}

This section describes the design and implementation of NAOMOBBY. NAOMOBBY includes different modules such as configuration, user and therapy management, motion reproduction and results. To document properly the NAOMOBBY development process, the RUP [21] methodology was used. Due to space reasons, this paper includes part of RUP documents.

\section{A. Design of NAOMOBBY}

Considering the related works described in Section II, NAOMOBBY was developed to satisfy the following functional and non-functional requirements:

Functional requirements: therapists can configure the motion and communication parameters of the NAO robot; to use the robot voice synthesizer to encourage patients along the therapy; therapists can use the GAS (Goal Attainment Scale) scale [5] to measure the therapy progress; to support data persistence in a SQL-based database; therapists can add, modify and delete movements, patients and therapeutic goals; therapists can visualize new motions on the GUI; therapists can play the motions of the physical rehabilitation therapy; therapists can introduce grades of each therapeutic goal according to GAS; and, therapists can get a report of the therapy progress.

Non-functional requirements: robot NAO, robot simulator Choreograph 2.1.4, programming language Python 2.7, SLQLite as local data base, and Kinect sensor to obtain the therapist/patient motions.

To satisfy these requirements, it is important to observe how they interact with the software actors. Fig. 2 shows the NAOMOBBY conceptual diagram, its interaction with users, and the NAO robot. In figure 2, therapists can manage motions, goals and patients; therapists can perform the system configuration, as well as saving and showing results obtained in the physical therapy. Also, therapists can play the preprogrammed robot motions, or perform a free motion session in order to get familiar with the software tool. As observed in Fig. 2, NAOMOBBY uses a SQL database to store all therapy information, and NAOMOBBY was conceived as a threemodule software namely: configuration and management, motion reproduction and results.

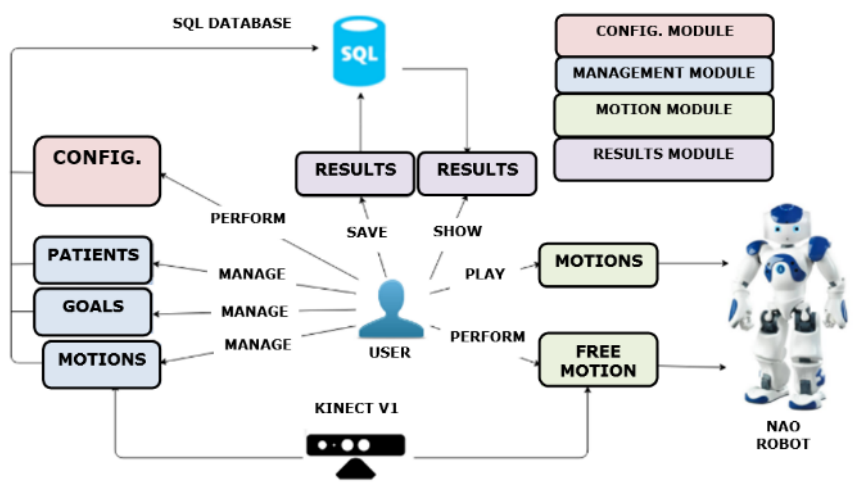

Fig. 2. Conceptual diagram

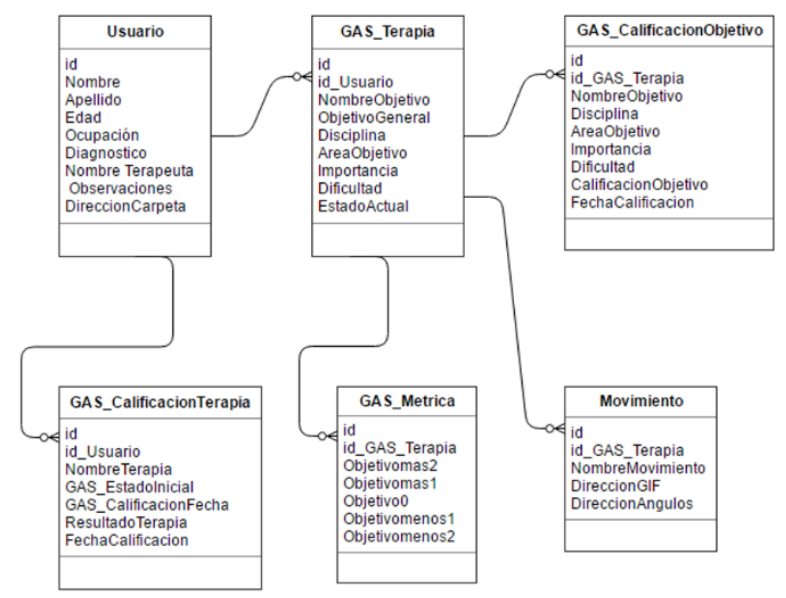

Fig. 3. Relational data model

Motion tracking system is crucial for this work; this can be observed in Table 1. NAOMOBBY uses a Kinect sensor as motion tracking system since it is the suitable candidate in clinical applications with children who have physical rehabilitation therapies [20]. Other motion tracking systems such as IMU-based or multi-camera based systems have better accuracy, but they could be intrusive for some patients; since these systems need markers on the patient's body [20]. In addition, the Kinect sensor in comparison with these motion systems do not need a setup or calibration phase; as a result, the Kinect sensor is a better option for NAOMOBBY.

Data persistence is an important requirement as can be observed in Table 1. Fig. 3 shows the relational data model implemented in NAOMOBBY. This model has 5 tables, the users table stores personal information about patients; each patient has its own therapeutic goals, these goals are stored in GAS_Therapy table; in this table, other information required in the GAS metric [5] is also stored; each therapeutic goal is quantitatively measured and this information is stored in the GAS_Metric table. The motions corresponding to the patient physical therapy are stored in Motions table; the summary of goal grades obtained in the physical therapy are stored in the GAS_Goal table; finally, the GAS_TherapyGrade table stores 
the quantitative grading of all activities performed in the physical rehabilitation process.

RUP methodology for software development includes other design documentation such as real use cases, sequence diagrams and class diagrams. All these documents cannot be shown in this paper due space reasons.

\section{B. Graphical User Interface Description of NAOMOBBY}

To implement NAOMOBBY, the functional requirements were divided in three modules namely configuration and management, motion reproduction and results.

Configuration and Management Module - In first place, Fig. 4a shows the NAOMOBBY GUI shown when a therapist opens the software tool. The GUI includes a tool bar (No. 1), a status message showing the current user and the therapy goal (No. 2), and three tabs corresponding to the modules as follows: configuration and management (No. 3), motion reproduction and therapy qualification (No. 4), and results (No. 5).

The tool bar in Fig. 4a allows therapist managing (create, modify, delete) patients, therapy goals and motions, enabling the free motion mode, and configuring NAO robot parameters such as: IP address, port number, motion speed, and amount of time between motions.

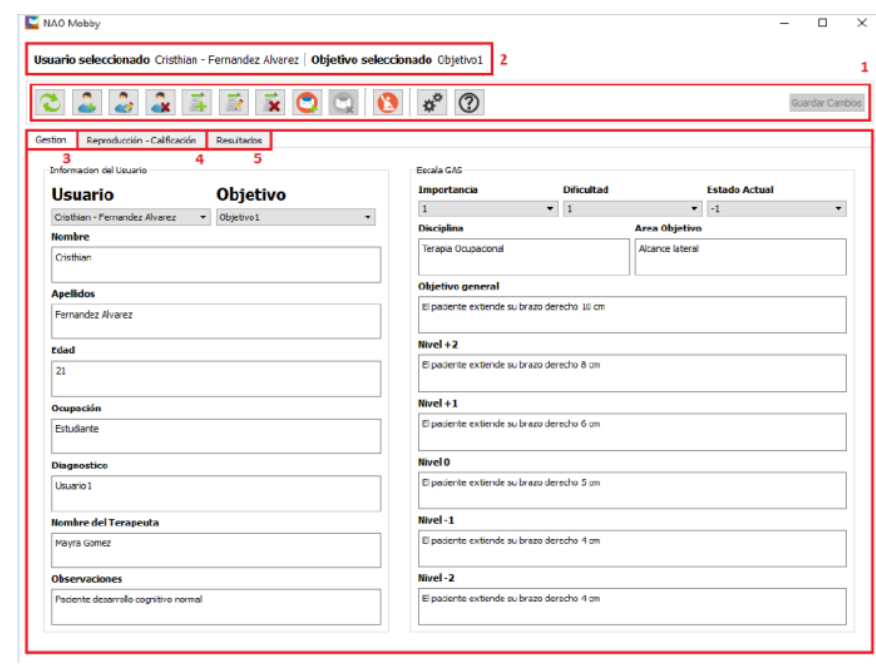

a)

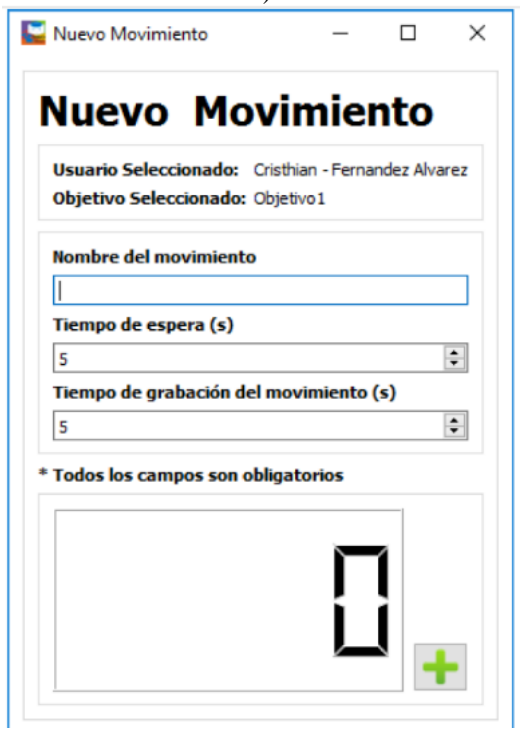

b)

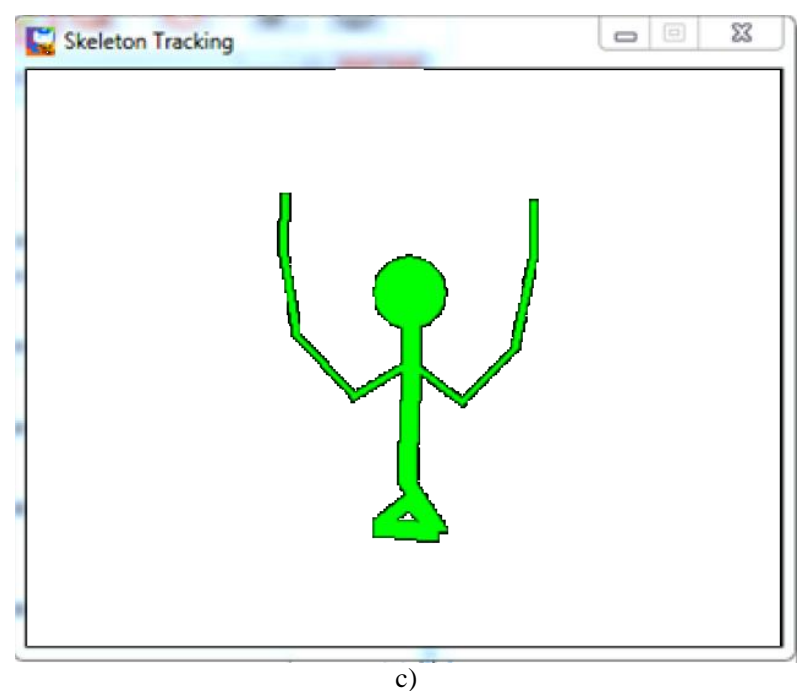

Fig. 4. a) NAMOBBY GUI. b) New movement GUI. c) Skeleton tracking.

The free motion mode is normally used to become familiar with NAOMOBBY. It shows in real time the user skeleton avatar, and any movement performed by the user is imitated by the NAO robot.

Then, the therapist selects the patient name, and therapy goal in case they exist. Otherwise, the can create them. In addition, the therapist can modify the current information available for the patient and therapy goal. The right part of Fig. 4a shows the GUI with the current information of the therapy goal. This goal is described in the contexts of GAS methodology. In this context, a therapy goal includes: relevance level (0 to 3 ), difficulty level (0 to 3 ), current state (-2 to 2 ), type of discipline and area, a description of the therapy goal, and a set of descriptions related with motions expected at each GAS level ( -2 to 2$)$.

Once the therapy goal is selected, or created, the therapist can select or create a desired motion to be performed by the patient. Fig. 4b shows the GUI displayed to create a new motion. Here, the patient name and therapy goal are taken from the previous process; then, the therapist have to digit a name for the new movement, the waiting time before start recording, and the motion recording time. Afterwards, when the therapist press ' + ', the first countdown is shown and the therapist should stand in front of the Kinect sensor; after that, the second countdown is shown corresponding to the motion recording time. Then, other GUI is shown to validate the motions by the therapist as depicted in Fig. 4c; if the new movement is accepted, it is saved in the database.

The next step is motion reproduction, but before that, it is important to understand the method used in this work to measure the opening and rotation angles of patient's shoulder, and elbow. It is important since this method allows moving the NAO robot according with the patient's movements.

The Kinect sensor estimates 20 different joints in the human body in space [22]. In this work, the shoulder, elbow, wrist joints of both arms and hips are only used. Then, we used (1) to compute the opening and rotation angles.

$\theta=\operatorname{arcos}\left(\frac{\vec{A} \cdot \vec{B}}{\|\vec{A}\|\|\vec{B}\|}\right)$ 
Where, $A$ and $B$ are two vectors in space, and $\theta$ the angle between them. It is worth noting that Fig. 5 shows vectors computed with respect the Kinect sensor, and Fig. 5a shows the vectors used to compute the shoulder opening angle. In this case, $A$ vector corresponds to the hip joints, and $B$ vector is formed using the shoulder and elbow joints. In order to get an opening angle between $0^{\circ}$ and $90^{\circ}, 90^{\circ}$ is added to the result obtained from (1).

Fig. $5 \mathrm{~b}$ shows the vectors needed to compute the shoulder rotation. $A$ vector is formed using the shoulder and elbow joints, and $B$ vector is defined using the shoulder and hip joints. In this case, this angle ranges from $0^{\circ}$ to $180^{\circ}$ as depicted in Fig.5b.

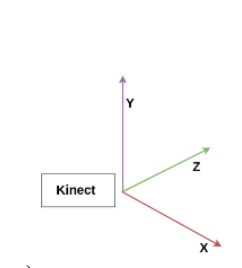

a)
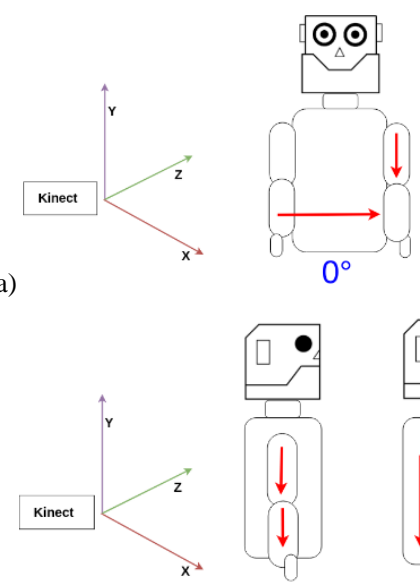

b)

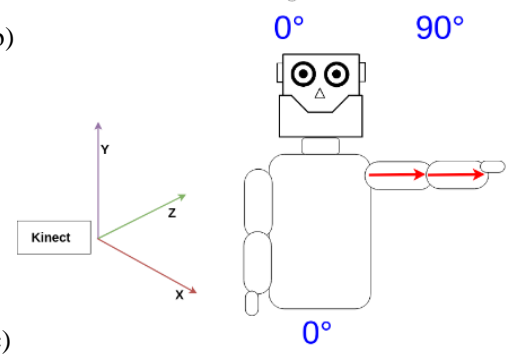

c)
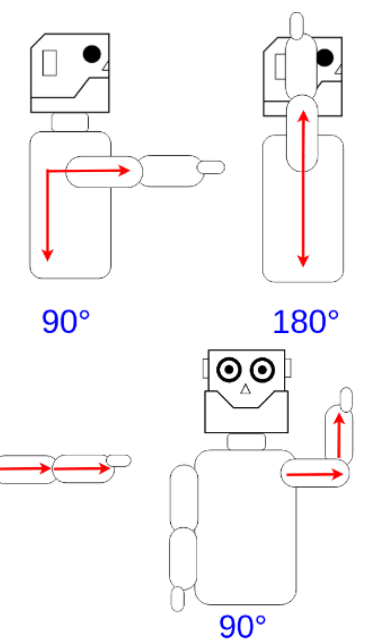

$80^{\circ}$

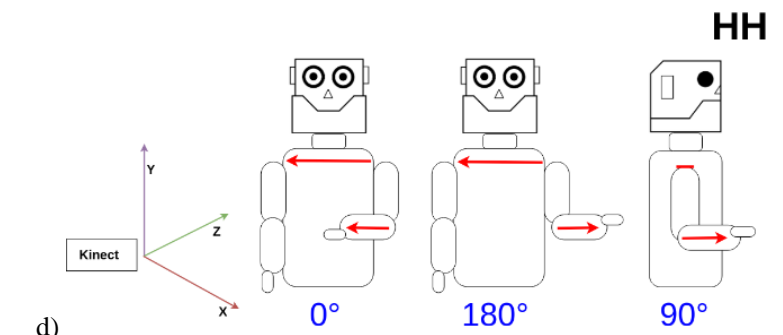

d)

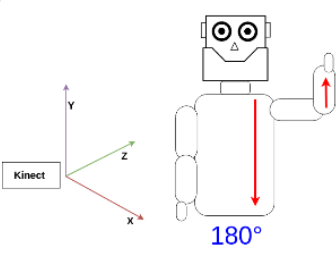

$180^{\circ}$

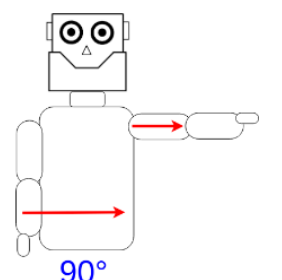

e)

Fig. 5. Vectors used to compute: a) Shoulder opening; b) shoulder rotation; c) Elbow opening; d) Elbow opening with shoulder low; e) Elbow opening with shoulder high

Fig. 5c shows the vectors used to compute the elbow opening angle. Here, $A$ vector is defined between the shoulder and elbow joints, and $B$ vector is formed between the elbow and wrist joints. In this case, this angle will be $0^{\circ}$ when the arm is extended, and $90^{\circ}$ when it is contracted.
Fig. 5d and 5e show two cases to select the vectors properly to compute the elbow rotation angle. This angle depends on shoulder opening angle. Then, the reference vector selected changes depending if the arm is close or far to patient's body (Fig. $5 \mathrm{~d}$ and $5 \mathrm{e}$ respectively). In the first case, the $A$ vector is defined between both shoulders, and vector $B$ is formed between the elbow and wrist joints. In the second case, the $A$ vector is defined between the shoulder and hip joints, and $B$ vector is formed as described above. Combining these two measurements, the calculation of the elbow rotation angle is depicted in (2).

$$
\theta_{E}=\theta_{S C} \frac{\theta_{S O}}{90^{\circ}}+\theta_{S F}\left(1-\frac{\theta_{S O}}{90^{\circ}}\right)
$$

Where, $\theta_{\mathrm{SC}}$ and $\theta_{\mathrm{SF}}$ are the measurements of elbow angle when shoulder is close (SC) or far (SF), $\theta_{\mathrm{So}}$ is the shoulder opening angle, and $\theta_{\mathrm{E}}$ is the elbow rotation angle. Basically, if $\theta_{\text {so }}$ is close to $90^{\circ}$, the second term of (2) is negligible, in this case $\theta_{\text {SC }}$ prevails; otherwise, if $\theta_{\text {So }}$ is close to $0^{\circ}$, the first term of (2) is negligible, then $\theta_{\text {SF }}$ prevails.

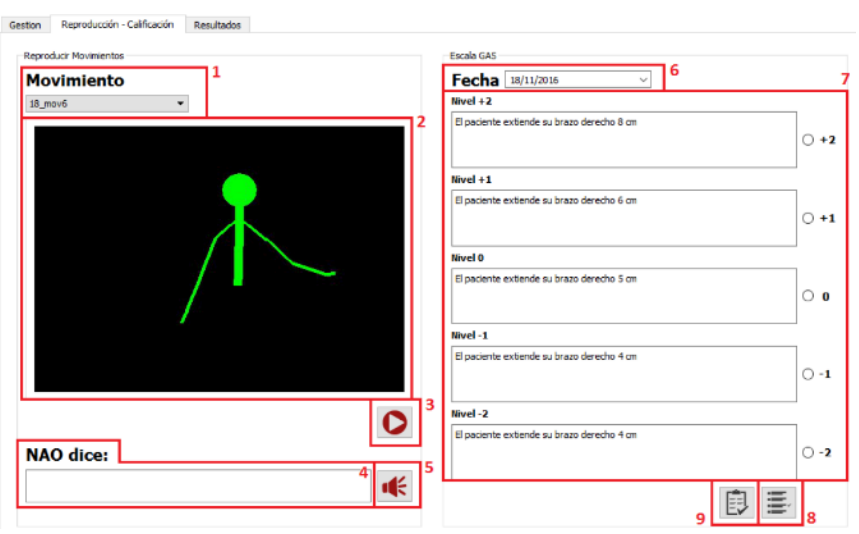

Fig. 6 Motion reproduction and qualification module.

Once the joint angles measurement method was described, the next step for a therapist is the motion reproduction and qualification module. Fig. 6 shows its GUI. In this module the therapist can select the motion to perform (No. 1), visualize an animated GIF of the movement (No. 2), reproduce the movement selected (No. 3), introduce a text to be reproduced by the NAO robot (No. 4, 5), select the date of the physical therapy (No. 6), select the qualification of the therapeutic goal (No. 7), save the therapeutic goal qualification (No. 8), and qualify the physical therapy.

The physical therapy qualification is done using the GAS methodology. Normally, each therapy has various therapeutic goals. Then, according with GAS [5] the total therapy qualification can be obtained using (3).

$T_{G A S}=50+\frac{10 \sum w_{i} x_{i}}{\sqrt{(1-p) \sum w_{i}^{2}+p\left(\sum w_{i}\right)^{2}}}$

Where, $w_{i}$ is the weight assigned at each qualification level of therapeutic goal $i ; x_{i}$ is the qualification level of goal $i$, and $p$ is the expected correlation, normally assumed as 0.3 [5]. In the GAS methodology, (4) is used to measure the patient physical therapy improvement at each session. 
$T_{\text {GASimp }}=T_{\text {GAS }}-T_{\text {GASBase }}$

Where, $T_{G A S}$ is obtained from (3), and $T_{\text {GASBase }}$ is defined as the patient's initial state, which is normally measured using the patient's initial values for each therapeutic goal.

At each moment the therapist qualifies a therapy, NAOMOBBY stores in the local database the new results for each therapeutic goal.

At the end of any session of the physical therapy, therapists can observe the evolution of the therapy process by therapeutic goal in the results module. Fig. 7 shows the results module GUI. Here, therapists can select the therapeutic goal (No. 1), and to obtain a graph (No. 2) of the GAS results of equation (4) versus the session date. In addition, therapist can perform the following operations on the graph results (No. 3-10): going forward and back, zooming, saving, changing the axis and graph properties.

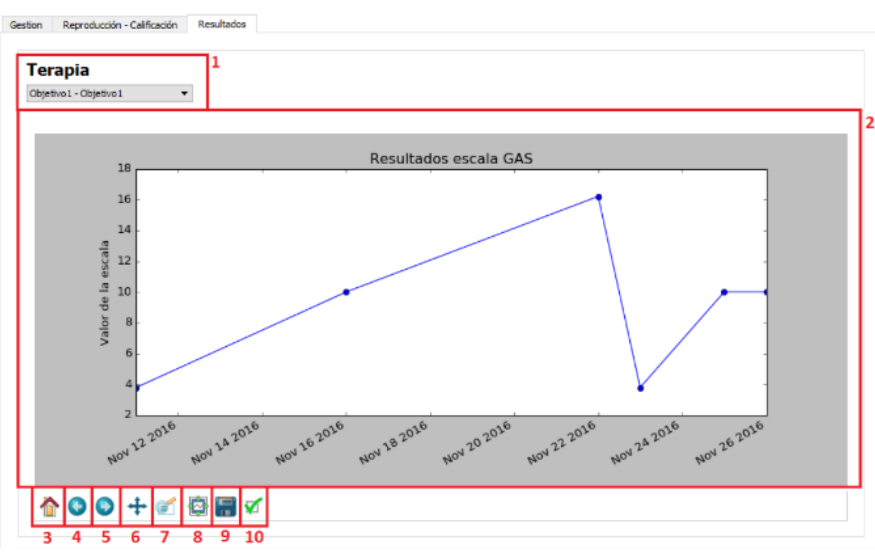

Fig. 7 Results module.

\section{TEST AND RESUltS}

The results reported with NAOMOBBY involves two kind of tests: first, quantitative tests in order to check the accuracy of motion reproduction, which is sensed using the Kinect sensor and performed by the NAO robot (Section IV.A). And second, field test with real users in a physical therapy scenario at the neuro-rehabilitation center SURGIR (Cali, Colombia) (Section IV.B). The latter test was performed using functional motions in six children with cerebral palsy type two. All these therapy sessions were attended by different therapists, who interacted with NAOMOBBY and fill the survey.

\section{A. Quantitative Results}

As depicted in Table 1, accurate user feedback is important to encourage empathy with the therapy process. In this work, patient feedback is achieved using audio messages reproduced by robot and configured by therapist, and patient's motion perceived by the Kinect sensor. The latter is used to compute how close the patient's motions are with respect the NAO robot motions. Here, the NAO robot motions are programmed by imitation of the therapist as described in Section III.B. Then, in this way, NAOMOBBY can compute quantitatively if patient motion performed well or not with respect the therapy motions stored in the database.
To do so, the field tests were performed using basic functional motions as follows [3]: left arm extended, left arm extended upwards, and right arm on the body, elbow rotated inwards. These motions were selected by two reasons: first, they are fundamental to perform other more complicated functional motions [3]; and second, they allow performing good joint measures while users are in front of the Kinect sensor.

Then, the process to obtain the quantitative results is described as follows:

1. NAOMOBBY is started in free motion mode.

2. In order to measure the angles in the NAO robot, Choreograph [23] software was used.

3. User stands in front of the Kinect sensor.

4. Finally, user performs the motion and stand by for a few seconds to acquire thirty angle readings.

This process was repeated by the three motions described above. Fig. 8a, 8c, and 8e show the three motions used to measure the NAOMOBBY motion reproduction. These figures show the skeleton representation of the Kinect sensor for upper limbs. These motions involve the left and the right arm as well.

Then, it is important performing the measurements in various joints namely: left shoulder opening (join No. 1) and rotation (join No. 2), left elbow opening (join No. 3) and rotation (join No. 4), right shoulder opening (join No. 5) and rotation (join No. 6), right elbow opening (join No. 7) and rotation (join No. 8). Fig. 8b, $8 \mathrm{~d}$ and $8 \mathrm{f}$ show the relative error graphs for each motion. In these graphs, the continuous line corresponds to the mean value, and the dashed lines correspond to the standard deviation values.

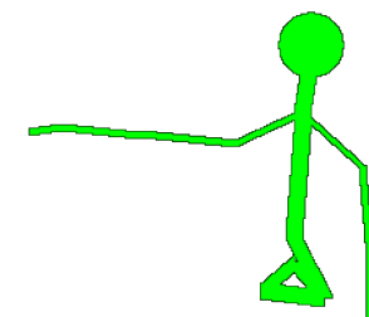
a)

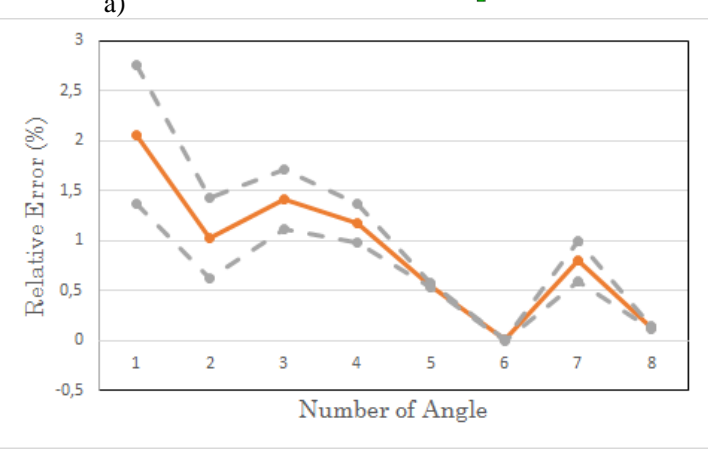

b) 


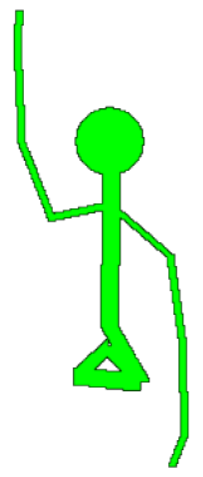

c)

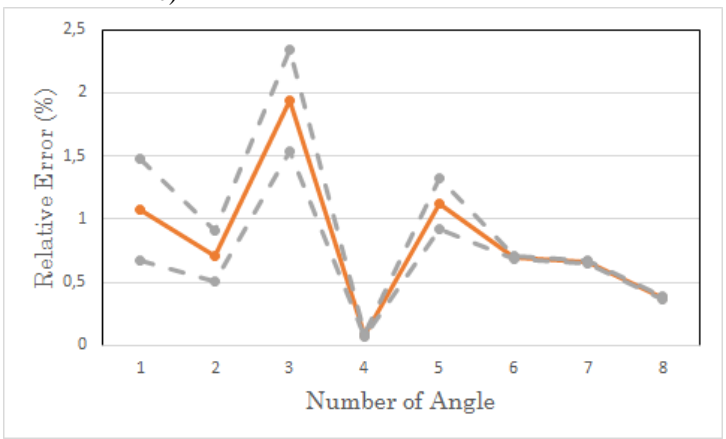

d)

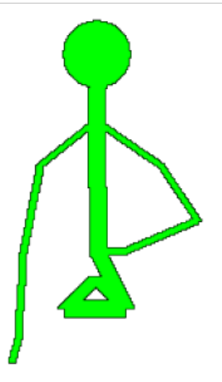

e)

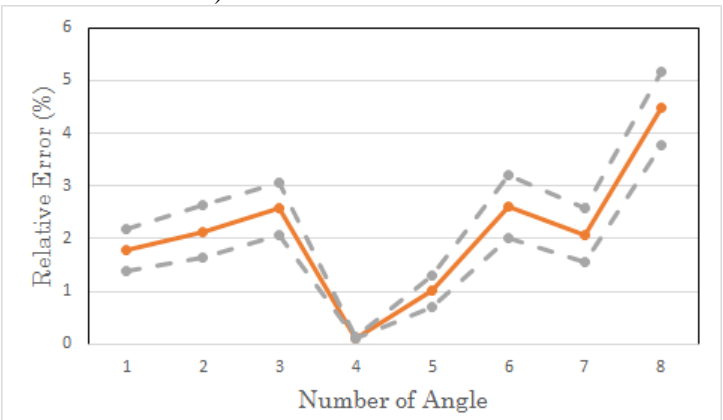

f)

Fig. 8 Motions sensed by the Kinect sensor and corresponding relative errors: a), b) Left arm extended, c), d) Left arm extended upwards, and e), f) right arm on the body, elbow rotated inwards.

In general, these results show maximum values of $3 \%$ of relative error, except in the last motion where a maximum error value of 5\% was achieved. In addition, the mean square error for these three motions are $0.373 \%, 0.096 \%$, and $1.129 \%$ respectively. These results show that the Kinect sensor was the proper option for our purposes, which also was demonstrated in [20]; then, low errors in motion tracking increase biofeedback perception on patients.

Considering the experimentation experience with the Kinect sensor and the NAO robot, the error sources are listed as follows: first, the NAO robot has construction constraints into its joints, especially in the opening motion; second, it is important to place the patient at a distance between $1 \mathrm{~m}$ and $2.5 \mathrm{~m}$ of the Kinect sensor, in addition the Kinect sensor should not have any relative orientation with respect the patient; and third, the patient should not have any relative orientation with respect the Kinect sensor. These source of errors can be minimized taking into account basic operational actions at the moment of performing the physical therapy.

\section{B. Field Results}

The field tests were performed at the neuro-rehabilitation center SURGIR in Cali, Colombia. Following was the process performed to do these tests:

1. In first place, the NAOMOBBY software tool was introduced to the therapist group. This introduction included: the NAOMOBBY GUI, the Kinect sensor, and the NAO robot.

2. Then, therapists used the NAOMOBBY software tool to define the therapeutic goals for each patient. Here, therapists suggested focusing the physical rehabilitation therapies on functional motions such as: right arm front extension, right and left arm extension upwards. These functional motions were selected since they are fundamental for achieving independence of patients in daily live tasks [3].

3. Afterwards, six different physical rehabilitation sessions were scheduled with the patients and their relatives. It is worth noting that NAOMOBBY is a software tool handled by therapists, then, in this context there are few cases where exits available therapists, and patients with cerebral palsy willing to perform this kind of physical therapy.

4. At the end of the therapy process, therapists were asked to fill a survey. The aim of this survey is to evaluate the NAOMOBBY GUI, the automatic process to qualify a physical therapy using GAS, and the NAOMOBBY interaction tools.

The survey performed to the therapists has 14 questions, they are listed as follows:

1. What do you think about the NAOMOBBY GUI? (Multiple selection) Answers: Nice, Intuitive, Novel, Confusing, Unpleasant.

2. How much do you agree with the graphical contents selection of NAOMOBBY? Answers: Totally, Agree, Partially, Not Agree.

3. Using a scale of 1 to 5 , being 5 the best, what do you think about the NAOMOBBY GUI navigability?

4. How easy was for you adding, modifying or deleting patients? Answers: Very Easy, Easy, Difficult, Very Difficult.

5. How easy was for you adding, modifying or deleting therapeutic goals? Answers: Very Easy, Easy, Difficult, Very Difficult.

6. How easy was for you adding, modifying or deleting motions? Answers: Very Easy, Easy, Difficult, Very Difficult.

7. How easy was for you qualifying therapeutic goals? Answers: Very Easy, Easy, Difficult, Very Difficult.

8. How easy was for you qualifying therapies? Answers: Very Easy, Easy, Difficult, Very Difficult. 
9. Using a scale of 1 to 5 , being 5 the best, do you think previsualize the robot motion was useful?

10. Using a scale of 1 to 5 , being 5 the best, do you think visualizing the therapy results using GAS was useful?

11. Using a scale of 1 to 5 , being 5 the best, do you think using the free mode was useful?

12. Which interaction ways of NAOMOBBY caught your attention? (Multiple selection) Answers: Body Gestures, Voice Synthesizer, Robot lights

13. Using a scale of 1 to 5 , being 5 the best, do you think NAOMOBBY could be an option to support physical therapies of upper limps?

14. Using a scale of 1 to 5 , being 5 the best, in general, how do you qualify your experience with NAOMOBBY?

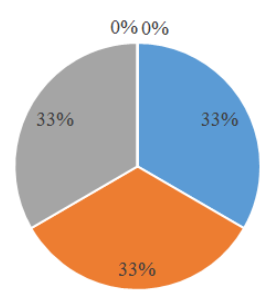

a)

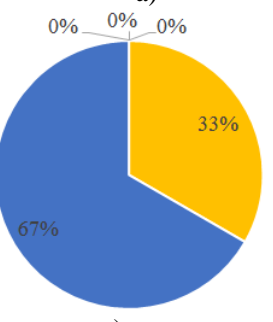

c)
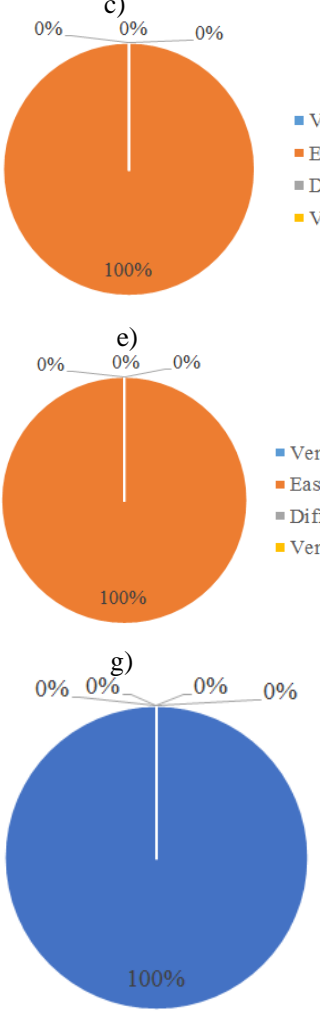

i)
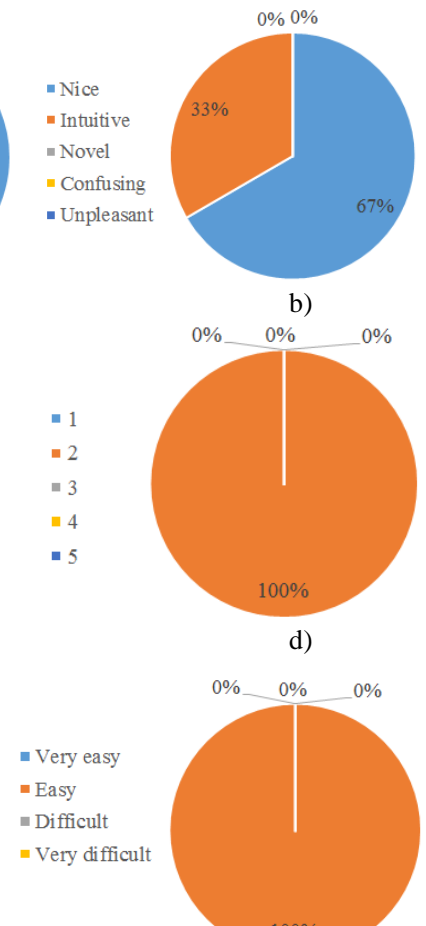

- Totally

- Agree

= Partially

- Not Agree

b)

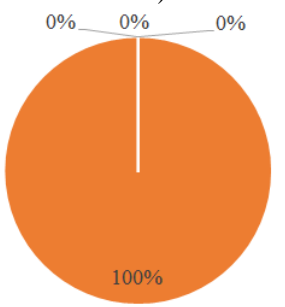

d)

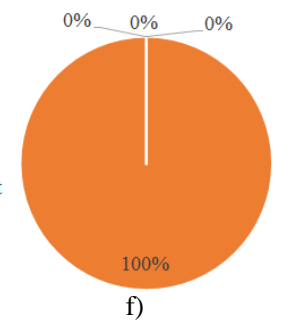

- Very easy

- Easy

- Difficult

" Very difficult
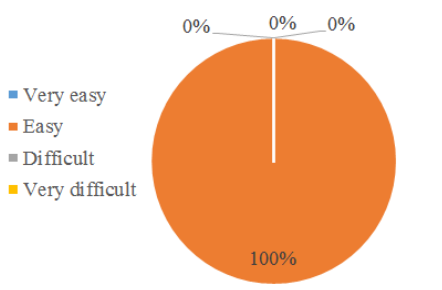

- Very easy

- Easy

- Difficult

" Very difficult

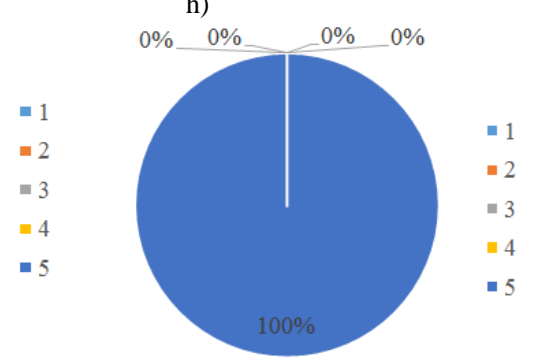

j)

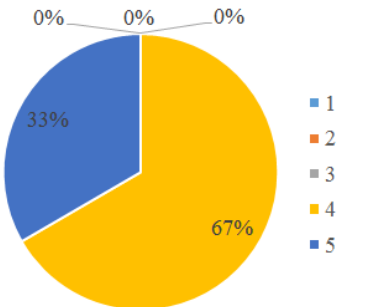

k)

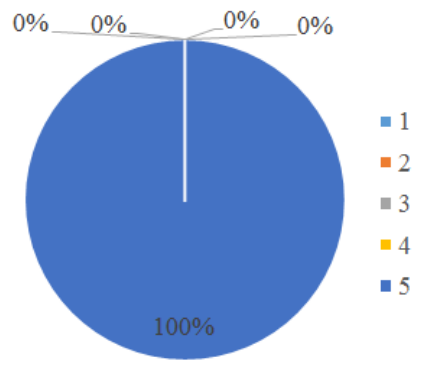

m)

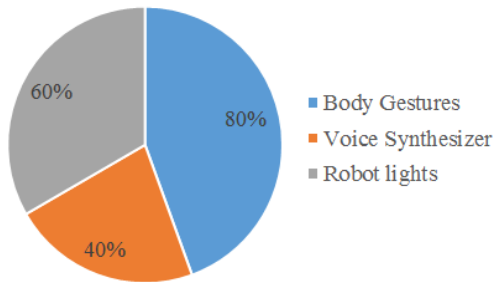

1)

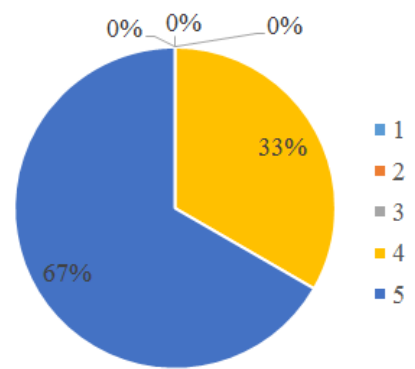

n)

Fig. 9. Survey results. a) Question 1. b) Question 2. c) Question 3. d) Question 4. e) Question 5. f) Question 6. g) Question 7. h) Question 8. i) Question 9. j) Question 10. k) Question 11. 1) Question 12. m) Question 13. n) Question 14.

Fig. 9 shows the survey results for each question asked to the therapists. Results depicted in Fig. 9a, 9b and 9c show evidence about how friendly is the NAOMOBBY GUI. Then, considering these results NAOMOBBY is a nice and novel software tool with suitable graphical contents, and practical navigation schema.

Fig. 9d, 9e, 9f, 9g, and $9 \mathrm{~h}$ provide evidence of how easy is performing important functional task such as managing patients, therapeutic goals and motions, qualifying goals and therapies. This also shows that users (therapists) appreciate to get trackable results in the therapy process

NAOMOBBY has important features which make difference in comparison with other software tools. Fig. $9 \mathrm{i}, 9 \mathrm{j}$ and $9 \mathrm{k}$ help to understand how important are features such as pre-visualization motion, using GAS to qualify goals and therapies, and usefulness of the free motion mode. In this context, Fig. 91 shows what interaction ways are preferred by therapists to perform the physical therapy, in order of importance these are: body gestures, robot lights, and voice synthesizer.

In general, the user experience using NAOMOBBY is also evaluated. It is very important to measure the acceptance of this kind of applications to support the physical rehabilitation process. Fig. $9 \mathrm{~m}$ and $9 \mathrm{n}$ show evidence of this. As depicted in Fig. 9m, therapists find very important involving software applications as NAOMOBBY in the physical rehabilitation therapies; as well as, in general the experience with NAOMOBBY was very positive.

Finally, therapists were interested in using NAOMOBBY in physical rehabilitation therapies involving other functional motions such as: hands to the head, hand to the mouth, and hand to the chest. These motions are important to bring more independence to patients with cerebral palsy in daily life activities such as: rise, reach or grab objects, brushing teeth, comb oneself, and get dressed. 


\section{CONCLUSIONS}

This paper presented the design and implementation of NAOMOBBY. This software tool can be used to support physical rehabilitation therapies of shoulder, elbow and wrist. NAOMOBBY includes a GUI for therapists, the Kinect sensor to measure the patient motions, and the NAO robot as biofeedback method for patients.

NAOMOBBY was developed considering the RUP methodology of software engineering. NAOMOBBY GUI includes three modules namely configuration and management, motion reproduction and results. Patients rehabilitation therapies and its results are conceived into the GAS framework, which enables measuring the patient progress over therapies.

NAMOBBY was tested performing two kind of tests. First, quantitative results were obtained using three basic functional motions such as: left arm extended, left arm extended upwards, and right arm on the body, elbow rotated inwards; the mean square error for these three motions were $0.373 \%, 0.096 \%$, and $1.129 \%$ respectively. Second, field tests were performed at the neuro-rehabilitation center SURGIR in Cali, Colombia; where six different rehabilitation sessions were scheduled with patients with cerebral palsy. The surveys filled at the end of these therapies bring the following results: NAOMOBBY is a nice and novel software tool with suitable graphical contents, it was easy to use by therapist, it offers important tools to previsualize therapy motions, quantify the patient progress using GAS and NAOMOBBY allows interact with patients using the NAO robot motions, lights and voice synthesizer.

Finally, future works include: communication functionalities in such a way reports and results are sent by email (this suggestion was done by a therapist), and developing a virtual robot such that patients continue physical rehabilitation therapies at home. In addition, involving NAOMOBBY software tool in new studies to evaluate the effect, and impact of the fulfillment of therapeutic objectives using GAS.

\section{ACKNOWLEDGEMENTS}

This work was partially funded by the research project "Methodological proposal to use robotics in therapies to develop physical and cognitive skills in children with motor disability" contract CI2851 of the Universidad del Valle.

\section{REFERENCES}

[1] DANE, "Censo General," Bogotá, Colombia, 2010.

[2] K. Smith and K. Smith, “ ," Digit. Outcasts, pp. 125-155, DOI: 10.1016/B978-0-12-404705-1.00006-6 Jan. 2013.

[3] B. H. Connolly and P. Montgomery, Therapeutic exercise in developmental disabilities. SLACK, 2005.

[4] C. Plaisant et al., "A storytelling robot for pediatric rehabilitation," in Proceedings of the fourth international ACM conference on Assistive technologies - Assets '00, 2000, pp. 50-55, DOI: $10.1145 / 354324.354338$.

[5] Z. Mailloux et al., "Goal attainment scaling as a measure of meaningful outcomes for children with sensory integration disorders.," Am. J. Occup. Ther., vol. 61, no. 2, pp. 254-9.

[6] H. S. J. de Déu, "El Hospital Sant Joan de Déu es pionero en el uso de los robots en hospitales infantiles," 2016. [Online]. Available: https://faros.hsjdbcn.org/es/noticia/hospital-sant-joan-deu-pionerouso-robots-hospitales-infantiles. [Accessed: 06-Nov-2018]. https://www.hocoma.com/solutions/armeo-spring/. [Accessed: 06Nov-2018].

[8] Y.-H. Peng, C.-W. Lin, N. M. Mayer, and M.-L. Wang, "Using a humanoid robot for music therapy with autistic children," in 2014 CACS International Automatic Control Conference (CACS 2014), 2014, pp. 156-160, DOI: 10.1109/CACS.2014.7097180.

[9] M. A. Miskam, S. Shamsuddin, H. Yussof, I. M. Ariffin, and A. R. Omar, "A questionnaire-based survey: Therapist's response on emotions gestures using humanoid robot for autism," in 2015 International Symposium on Micro-NanoMechatronics and Human Science (MHS), 2015, pp. 1-7, DOI: 10.1109/MHS.2015.7438298.

[10] N. A. Malik and F. A. Hanapiah, "Development of Imitation Learning through Physical Therapy Using a Humanoid Robot," Procedia Comput. Sci., vol. 42, pp. 191-197, Jan. 2014, DOI: 10.1016/J.PROCS.2014.11.051.

[11] A. R. Taheri, M. Alemi, A. Meghdari, H. R. PourEtemad, and N. M. Basiri, "Social robots as assistants for autism therapy in Iran: Research in progress," in 2014 Second RSI/ISM International Conference on Robotics and Mechatronics (ICRoM), 2014, pp. 760766, DOI: 10.1109/ICRoM.2014.6990995.

[12] C. McCarthy, A. Scheinberg, F. Marti, J. Butchart, and L. Sterling, "Robots can help young patients engage in rehab," 2016. [Online]. Available: http://theconversation.com/robots-can-help-youngpatients-engage-in-rehab-54741. [Accessed: 06-Nov-2018].

[13] G. Altanis, M. Boloudakis, S. Retalis, and N. Nikou, "Children with M otor Impairments Play a Kinect Learning Game: First Findings from a Pilot Case in an Authentic Classroom Environment," Interact. Des. Archit. J., vol. 19, pp. 91-104, 2013.

[14] N. Hamzeheinejad, S. Straka, D. Gall, F. Weilbach, and M. Erich Latoschik, "Immersive Robot-Assisted Virtual Reality Therapy for Neurologically-Caused Gait Impairments," in 2018 IEEE Conference on Virtual Reality and 3D User Interfaces (VR), 2018, pp. 565-566 DOI: $10.1109 /$ VR.2018.8446125.

[15] M. Alahbabi et al., "Avatar based interaction therapy: A potential therapeutic approach for children with Autism," in 2017 IEEE International Conference on Mechatronics and Automation (ICMA), 2017, pp. 480-484, DOI: 10.1109/ICMA.2017.8015864.

[16] K. Ogata, Y. Hirabayashi, K. Kubota, and T. Tsuji, "Home rehabilitation assist robot to facilitate isolated movements for hemiplegia patients," in 2017 IEEE/RSJ International Conference on Intelligent Robots and Systems (IROS), 2017, pp. 527-532, DOI: 10.1109/IROS.2017.8202203.

[17] J. C. González, J. C. Pulido, F. Fernández, and C. Suárez-Mejías, "Planning, execution and monitoring of physical rehabilitation therapies with a robotic architecture.," Stud. Health Technol. Inform., vol. 210, pp. 339-43, 2015.

[18] F. S. Alnajjar, A. M. Renawi, M. Cappuccio, and O. Mubain, "A Low-Cost Autonomous Attention Assessment System for Robot Intervention with Autistic Children," in 2019 IEEE Global Engineering Education Conference (EDUCON), 2019, pp. 787-792, DOI: 10.1109/EDUCON.2019.8725132.

[19] J. M. Beer, M. Boren, and K. R. Liles, "Robot assisted music therapy a case study with children diagnosed with autism," in 2016 11th ACM/IEEE International Conference on Human-Robot Interaction (HRI), 2016, pp. 419-420, DOI: 10.1109/HRI.2016.7451785.

[20] A. Geminiani et al., "Design and validation of two embodied mirroring setups for interactive games with autistic children using the NAO humanoid robot," in 2019 41st Annual International Conference of the IEEE Engineering in Medicine and Biology Society (EMBC), 2019, pp. 1641-1644, DOI: 10.1109/EMBC.2019.8857576. P. Kruchten, The Rational Unified Process: An Introduction, 3rd ed. Addison-Wesley Professional, 2003.

[22] Microsoft, "PyKinect - write Kinect games using Python." GitHub, p. 1, 2018.

[23] S. Robotics, "NAO - Softbank Robotics," 2018. [Online]. Available: https://www.softbankrobotics.com/emea/en/nao. [Accessed: 06Nov-2018]. 


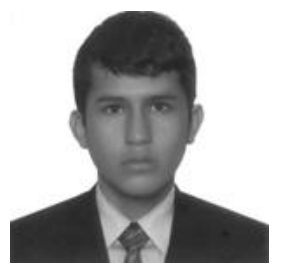

Cristian Fernández Álvarez got his degree on Electronic Engineering in 2017, he also is a master's degree student in engineering with emphasis on Automation at Universidad del Valle, Colombia. His interests are mobile robotics and computational intelligence, he is currently studying computational intelligence models for time series forecasting, working as an AI developer.

ORCID: https://orcid.org/0000-0002-9213-1301

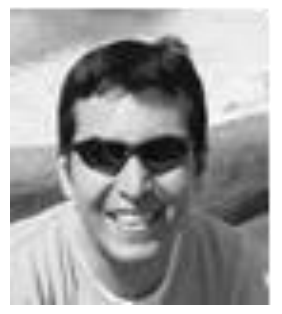

Bladimir Bacca Cortes got his degree on Electronic Engineering in 1999, he received his M.Sc. in 2004 both at the Universidad del Valle, Cali, Colombia. Received a Ph.D. at the University of Girona in 2012. He is a Professor of the Electrical and Electronic Engineering School at the Perception and Intelligent

Systems Group, Universidad del Valle. His current research interests are in the field of localization and mapping for mobile robots, computer vision, focusing on SLAM and appearancebased environmental models.

ORCID: https://orcid.org/0000-0003-0113-4134

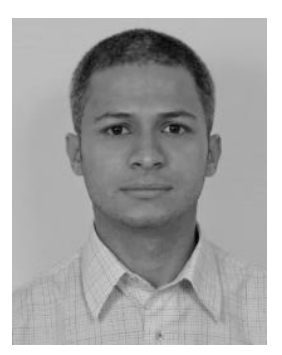

Jaime Alberto Buitrago Assistant Professor at the Universidad del Quindío, Electronic Engineer from the same University, Magister and Doctor of Engineering from Universidad del Valle. Member of the SINFOCI (Industrial Information and Control Systems) research group of the Universidad del Quindío. Areas of interest: Assistive Technologies for Rehabilitation, Robotics and Embedded Systems.

ORCID: https://orcid.org/0000-0002-8328-8470

CVLAC:

https://scienti.minciencias.gov.co/cvlac/visualizador/generarC urriculoCv.do?cod_rh=0000214205

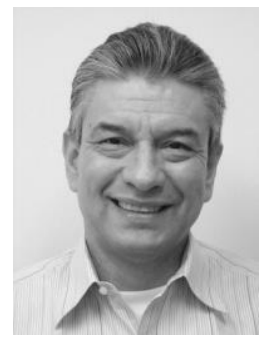

Eduardo Caicedo Bravo Electrical Engineer of the Universidad del Valle (1985), Master of Information Technology in Manufacturing (1993), Doctor Engineering Ph.D. in Industrial Informatics of the Polytechnic University of Madrid-Spain (1996). Professor at the Universidad del Valle and Director of the Research Group Perception and Intelligent Systems (PSI). Author of several books and scientific articles, guest speaker at national and international events and visiting professor at international universities. He has worked projects with COLCIENCIAS, The European Union, CYTED, the Swiss Confederation and national companies. Areas of Interest: Smart Grids, Instrumentation Electronics, Intelligent Systems, Computational Intelligence and Robotics.

ORCID: https://orcid.org/0000-0003-0727-2917 